\title{
Multiple origin of Aptian salt deposit in proximal domain of the West African Margin
}

Pichat AleXandre ${ }^{1}$, GaUCHer Eric C. ${ }^{2}$, ReVILlon SidoniE $^{3}$, Agrinier Pierre ${ }^{4}$, Lerouge CATHERINE ${ }^{5}$, FLEHOC CHRISTINE ${ }^{5}$,

${ }^{1}$ E2S-UPPA, IPRA, Univ. Pau \& Pays Adour; 64013, Pau, France (alexandre.pichat@gmail.com)

2 TOTAL, CSTJF, avenue Larribau, 64000 Pau, France

(eric.gaucher@total.com)

${ }^{3}$ SEDISOR, Plouzané, France (sidonie.revillon@sedisor.eu)

${ }^{4}$ IPGP, Paris, France (agrinier@ipgp.fr)

${ }^{5}$ BRGM, Orléans, France (c.flehoc@brgm.fr)

During the opening of the Central Altantic Ocean, the Aptian evaporites of the South Atlantic precipitated in a thousand kilometres-wide salt giant basin. The mineralogical assemblage of such evaporites in the Congo area is peculiar and still poorly understood. The salt section displays 11 stacked evaporite sequences mainly composed of halite and carnallite together with thick accumulations of bischofite and tahyhydrite. The evaporite section lacks sulphate minerals, excepts in its toppest part. We performed isotopic ananalysis on salt core samples in the proximal domain of the Congo basin to further constrain the parent water of the evaporites.

$\delta^{37} \mathrm{Cl}$ values of halite and carnallites ranges in those expected for a marine origin. On the opposite, $\mathrm{Pb}$ isotope values in similar minerals evidence a strong influence of crustal-derived water. Sr isotope values support a mixed parent water involving a marine water and a radiogenic-rich hydrothermal or continental water. Such Sr isotope data also evidence that the evaporite sequences reported in the salt section were controlled by repetitive marine ingressions probably resulting from eustatic variations. Moreover, $\mathrm{Cl}$ and $\mathrm{Sr}$ isotopic data suggests (i) recycling processes during the precipitation of bischofite and tachyhydrite or (ii) a third source of water which origin remains still to be constrained. Finally, as already reported in other salt basins, depletion in sulphate minerals together with the high content of $\mathrm{Ca}$, mandatory for the precipitation of tachyhydrite, probably result from fluid-rock interactions between marine water and the volcanic Walvis ridge that was confining the salt basin from the oceanic domain. Increasing sulphate occurrence in the toppest part of the salt section suggests progressive deconfinment from the oceanic domain before the establishment of an open marine environment, soon after the lithospheric breakup of the margin.

Ongoing new isotopic measurments $(\mathrm{S}, \mathrm{B}, \mathrm{Li}, \mathrm{H}$ and $\mathrm{O})$ should further shed light on the origin of the evaporites. 